\title{
PREVALENCE OF VITAMIN D INADEQUACY AMONG ORTHOPEDIC SURGEONS
}

\author{
Ongart Phruetthiphat, Nopphadon Kusuwannakul, Saradej Khuangsirikul, Teerapat Tutaworn, \\ Thawee Songpatanasilp, Thanainit Chotanaphuti
}

\author{
Department of Orthopaedics, Phramongkutklao Hospital and Phramongkutklao College of \\ Medicine, Bangkok, Thailand
}

\begin{abstract}
Background: Indoor workers including healthcare professionals are at high risk to develop vitamin D insufficiency and deficiency, due to lifestyle and limited sunlight exposure. Additionally, common health problems in aging men are vitamin D inadequacy, hypogonadism and prostate cancer.

Objective: The study aimed to determine the prevalence of vitamin D inadequacy, testosterone and prostate specific antigen (PSA) among orthopedic surgeons with different ages and regions of residence. Methods: This cross-sectional study was conducted at the annual meeting of the Royal College of Orthopedic Surgeons of Thailand (RCOST) in October 2017. All participants were orthopedic surgeons working in different regions in Thailand. They received blood examination for vitamin D (25-hydroxyvitamin D) levels, total testosterone and total PSA serum levels.

Results: A total of 257 orthopedic surgeons participated in the study. The prevalence of vitamin D inadequacy was $71.98 \%$. Old age group ( $\geq 60$ years old) had significantly higher total vitamin $D$ than young age group ( $<60$ years old) $(p=0.014)$. Participants from eastern region had significantly higher total vitamin $\mathrm{D}$ than Bangkok and southern regions $(p=0.015)$. Interestingly, the prevalence of low testosterone levels was $13 \%$ which occurred significantly in the age group $\geq 40$ year $(p=0.004)$. Additionally, the prevalence of high PSA levels was 4.67\%. Even though the old age group had significantly higher PSA than the young age group $(p<0.001)$, no correlation was found between region and total PSA level.

Conclusion: The prevalence of vitamin D inadequacy among Thai orthopedic surgeons was surprisingly high. This data provide important information to promote greater self-awareness to reduce the possible consequences associated with vitamin D inadequacy. Vitamin D supplementation including prevention strategies need to be promoted among healthcare professionals.
\end{abstract}

Keywords: Vitamin D inadequacy, Orthopedic surgeons, Prevalence, Elderly patients, Hypogonadism, Prostate cancer

J Southeast Asian Med Res 2021: 5(1):35-41

http://www.jseamed.org

Correspondence to:

Phruetthiphat O, Phramongkutklao Hospital and Phramongkutklao College of Medicine, Bangkok, Thailand

Email: ongart-phr1@hotmail.com,ophruetthiphat@gmail.com,

Received: 04 April 2021

Revised: 01 June 2021

Accepted: 09 June 2021 


\section{Introduction}

Vitamin D plays an important role not only in bone metabolism but also in a variety of nonskeletal diseases such as diabetes mellitus, autoimmune diseases, infectious diseases, cardiovascular diseases and cancer. ${ }^{(1)}$ Vitamin D inadequacy is now well documented as a contributing factor to muscle weakness including falls and fractures. ${ }^{(2)}$ High prevalence of vitamin D deficiency has been described in more than 1 billion people around the world, especially in the Middle East and $\mathrm{Asia}^{(3)}$ and it has been seen in all races, age groups and ethnic background. ${ }^{(4)}$ In Thailand, several studies have demonstrated the prevalence of vitamin D deficiency. Soontrapa et al. ${ }^{(5)}$ found that $66.3 \%$ of elderly Thai women, residing in Khon Kaen Province, had vitamin D deficiency [25(OH)D level $<35 \mathrm{ng} / \mathrm{mL}$ ] while the largest study of vitamin $\mathrm{D}$ status in a normal population $(\mathrm{N}=2641)$ identified overall $45.2 \%$ of vitamin D inadequacy. ${ }^{(6)}$ However, none of these studies focused on vitamin D inadequacy among Thai orthopedic surgeons. As we know, Thai orthopedic surgeons are predominantly male. Most are indoor workers at high risk to develop vitamin D inadequacy because their lifestyles and regular work at the hospital usually limited time to sunlight expose. Additionally, hypogonadism, a syndrome characterized by low serum testosterone levels, is a common disorder among aging men. Orthopedic surgeons who are at old age group could have a problem with hypogonadism and prostatic hypertrophy. Thus, this study aimed to define the prevalence of vitamin D inadequacy, hypogonadism and prostatic hypertrophy including prostate cancer among Thai orthopedic surgeons. Secondly, the study determined the relation of age and region of residence with total vitamin $\mathrm{D}$, total testosterone and total prostate surface antigen (PSA).

\section{Methods}

After obtaining Institution Research Board approval, this cross-sectional study was conducted at the annual meeting of the Royal College of Orthopedic Surgeons of Thailand (RCOST) October 2017. All Thai orthopedic surgeons including residents were asked to take blood examination of 25-hydroxyvitamin D (25-OH) level, total testosterone and total PSA serum levels. The data of ages and region of residence were collected. Participants were excluded when they presented history of hypovitaminosis D, late onset of hypogonadism, or prostate cancer.

Total $25-\mathrm{OH}$ vitamin $\mathrm{D}$ was evaluated and were classified in three categories; normal level (30-100 nanograms per milliliter; ng/mL), vitamin D insufficiency (21-29 $\mathrm{ng} / \mathrm{mL})$, and vitamin D deficiency $(<20 \mathrm{ng} / \mathrm{mL}) .{ }^{(4)}$ Considering the wide range of cut off values used for defining vitamin $\mathrm{D}$ inadequacy, less than $30 \mathrm{ng} / \mathrm{ml}$ was used as a threshold concentration of $25(\mathrm{OH}) \mathrm{D}$ for "vitamin D inadequacy", covering the definition of vitamin D deficiency and insufficiency together. Total testosterone levels were divided in two groups; normal level ( $\geq 8$ nanomole per liter; $\mathrm{nmol} / \mathrm{L})$ and low level $(<8 \mathrm{nmol} / \mathrm{L})$. Total prostate surface antigen (PSA) was categorized in two types: normal level (0-4 ng/mL) and high level $(>4 \mathrm{ng} / \mathrm{mL})$.

\section{Statistical analysis}

Data description was based on means and standard deviation for continuous variables and absolute and relative frequencies for categorical variables. A standard student's t-test was used for continuous variables while Chi-squared test and Fisher's exact test were applied for categorical variables. One-way ANOVA was used for continuous data and normal distribution while the Mann-Whitney U-test was applied for continuous data and uneven distribution. Statistical analysis was performed using STATA/MP 12 with statistical significance set at $p<0.05$.

\section{Results}

A total of 257 participants were recruited in this study. Participants' age and region of residence are demonstrated in Table 1; orthopedists with ages less than 40 years old totaled $53 \%(n=136)$, ages between 40 and 60 years old comprised 34\% $(n=87)$ and participants with ages more than 60 years old totaled $13 \%(n=34)$. In addition, the most common participants $(54.1 \%)$ came from Bangkok, the second most common (17.9\%) came from the northeastern region, followed by central region $(8.56 \%)$, eastern region $(7.4 \%)$, southern region $(6.2 \%)$, and northern region (5.8\%). 
Table 1. Baseline characteristics of the study population

\begin{tabular}{cc}
\hline Characteristic & N (\%) \\
\hline Age & $136(53)$ \\
$<40$ years & $87(34)$ \\
$40-60$ years & $34(13)$ \\
$>60$ years & $42.23 \pm 13.45$ \\
Mean \pm SD & $37(24-84)$ \\
Median (Minimum-Maximum) & \\
Region of residence & $139(54.1 \%)$ \\
Bangkok & $22(8.6 \%)$ \\
Central & $19(7.4 \%)$ \\
Eastern & $15(5.8 \%)$ \\
Northern & $46(17.9 \%)$ \\
Northeastern & $16(6.2 \%)$ \\
Southern &
\end{tabular}

Table 2. Level of 25-OH total vitamin D

\begin{tabular}{cc}
\hline 25-OH total vitamin D & N (\%) \\
\hline Deficiency $(<20)$ & $22(8.6 \%)$ \\
Insufficiency $(20-29)$ & $163(63.4 \%)$ \\
Normal $(\geq 30)$ & $72(28.0 \%)$ \\
Mean \pm SD & $27.4 \pm 6.7$ \\
Median (Minimum-Max) & $26.6(11.2-58.2)$ \\
\hline
\end{tabular}

Overall, the prevalence of vitamin D inadequacy among Thai orthopedic surgeons was $72 \%$. The prevalence of vitamin D insufficiency was $63.4 \%$, vitamin D deficiency was $8.6 \%$ while normal vitamin D level was $28.0 \%$ as shown in Table 2.

Vitamin D levels significantly differed among age groups (One-way ANOVA, $p=0.014$ ). The participants aged $>60$ years exhibited the highest vitamin D levels as shown in Table 3. Additionally, participants from different regions of Thailand showed significantly different Vitamin D levels (One-way ANOVA, $p=0.015$ ). Participants from the eastern area had the highest vitamin D levels while those from Bangkok revealed the lowest vitamin $\mathrm{D}$.
Overall, the prevelence of low level testosterone was $13.2 \%(n=34)$ while normal testosterone level was $86.8 \%(\mathrm{n}=223)$ as shown in Table 4. Testosterone level significantly differed among age groups (One-way ANOVA, $p=0.004$ ) as shown in Table 4. Additionally, age group $\geq 40$ years had a higher prevalence of low level testosterone than age group $<40$ years $(20.7 \%$ vs. $6.6 \%$, respectively). The participants from different regions of Thailand showed significantly different testosterone levels (One-way ANOVA, $p=0.04$ ). Those residing in Northern showed the highest testosterone levels while those residing in the Northeast showed the lowest levels. The prevelence of high level PSA was $4.7 \%(n=12)$ as shown in Table 5. PSA level significant differed among 
Table 3. Total vitamin D (25-OH) level classified by age and region of residence

\begin{tabular}{|c|c|c|c|c|c|}
\hline \multirow[t]{2}{*}{ Age group } & \multicolumn{5}{|c|}{ Vitamin D level (ng/mL) } \\
\hline & $\begin{array}{c}\text { Deficiency } \\
(<20)\end{array}$ & $\begin{array}{c}\text { Insufficiency } \\
(20-29.9)\end{array}$ & $\begin{array}{c}\text { Normal } \\
(\geq 30)\end{array}$ & Mean \pm SD & $\begin{array}{c}\text { Median } \\
(\text { Min-Max })\end{array}$ \\
\hline & $(n=22)(8.6 \%)$ & $(n=163)(63.4 \%)$ & $(\mathrm{n}=72)(28.0 \%)$ & & \\
\hline$<40$ years & $9(6.6 \%)$ & $91(66.9 \%)$ & $36(26.5 \%)$ & $27.1 \pm 5.9$ & $\begin{array}{c}26.5 \\
(14.4-46.5)\end{array}$ \\
\hline $40-60$ years & $10(11.8 \%)$ & $54(63.5 \%)$ & $21(24.7 \%)$ & $26.8 \pm 6.0$ & $\begin{array}{c}26.5 \\
(11.2-47.5)\end{array}$ \\
\hline$>60$ years & $3(8.3 \%)$ & $18(50.0 \%)$ & $15(41.7 \%)$ & $30.4 \pm 9.8$ & $\begin{array}{c}28.5 \\
(14.6-58.2)\end{array}$ \\
\hline$p$-value & & & & 0.014 & \\
\hline $\begin{array}{l}\text { Region of } \\
\text { residence }\end{array}$ & $\begin{array}{c}\text { Deficiency } \\
(<20)\end{array}$ & $\begin{array}{c}\text { Insufficiency } \\
(20-29.9)\end{array}$ & Normal $(\geq 30)$ & Mean \pm SD & $\begin{array}{c}\text { Median } \\
\text { (Min-Max) }\end{array}$ \\
\hline Bangkok & $20(14.60 \%)$ & $83(60.58 \%)$ & $34(24.82 \%)$ & $26.6 \pm 7.3$ & $\begin{array}{c}25.6 \\
(11.2-58.2)\end{array}$ \\
\hline Central & $1(5 \%)$ & $11(55 \%)$ & $8(40 \%)$ & $29.2 \pm 7.3$ & $\begin{array}{c}27.9 \\
(14.4-45.6)\end{array}$ \\
\hline Eastern & $0(0 \%)$ & $9(50 \%)$ & $9(50 \%)$ & $30.5 \pm 5.6$ & $\begin{array}{c}29.1 \\
(23.8-46.8)\end{array}$ \\
\hline Northern & $0(0 \%)$ & $7(53.9 \%)$ & $6(46.2 \%)$ & $28.7 \pm 6.2$ & $\begin{array}{c}29.4 \\
(20.1-42.8)\end{array}$ \\
\hline Northeastern & $0(0 \%)$ & $28(71.8 \%)$ & $11(28.2 \%)$ & $27.8 \pm 4.6$ & $\begin{array}{c}26.9 \\
(20.8-37.6)\end{array}$ \\
\hline Southern & $1(6.3 \%)$ & $11(68.8 \%)$ & $4(25 \%)$ & $26.8 \pm 6.4$ & $\begin{array}{c}25.6 \\
(18.5-37.7)\end{array}$ \\
\hline$p$-value & & & & 0.015 & \\
\hline
\end{tabular}

Total vitamin D (25-OH) level classified by age groups $(<40,40-60$ and $>60$ years old) was mainly divided into 3 types (vitamin D deficiency, insufficiency and normal levels). The prevalence of vitamin D inadequacy among Thai orthopedic surgeons was $72.0 \%$, vitamin D insufficiency was $63.4 \%$ and vitamin D deficiency was $8.6 \%$ while normal vitamin D level was $28.0 \%$.

Table 4. Testosterone level classified by age and living region

\begin{tabular}{|c|c|c|c|c|}
\hline \multirow[t]{2}{*}{ Age group } & \multicolumn{4}{|c|}{ Testosterone level } \\
\hline & $\begin{array}{c}\text { Low }(<8 \mathrm{nmol} / \mathrm{L}) \\
(\mathrm{n}=34)(13.2 \%)\end{array}$ & $\begin{array}{c}\text { Normal }(\geq 8 \mathrm{nmol} / \mathrm{L}) \\
(\mathrm{n}=223)(86.8 \%)\end{array}$ & Mean \pm SD & $\begin{array}{l}\text { Median } \\
\text { (Min-Max) }\end{array}$ \\
\hline$<40$ years & $9(6.62 \%)$ & $127(93.38 \%)$ & $14.82 \pm 5.79$ & $\begin{array}{c}13.30 \\
(5.08-40.50)\end{array}$ \\
\hline $40-60$ years & $18(21.18 \%)$ & $67(78.82 \%)$ & $12.41 \pm 5.97$ & $\begin{array}{c}11.40 \\
(3.83-35.90)\end{array}$ \\
\hline$>60$ years & $7(19.44 \%)$ & $29(80.56 \%)$ & $12.54 \pm 4.64$ & $\begin{array}{c}12.15 \\
(5.19-22.20)\end{array}$ \\
\hline$p$-value & & & 0.004 & \\
\hline Bangkok & $23(16.55 \%)$ & $116(83.45 \%)$ & $13.44 \pm 6.40$ & $\begin{array}{c}12.20 \\
(3.8-40.50)\end{array}$ \\
\hline
\end{tabular}


Table 4. Testosterone level classified by age and living region (Continue)

\begin{tabular}{|c|c|c|c|c|}
\hline \multirow[t]{2}{*}{ Age group } & \multicolumn{4}{|c|}{ Testosterone level } \\
\hline & $\begin{array}{c}\text { Low }(<8 \mathrm{nmol} / \mathrm{L}) \\
(\mathrm{n}=34)(13.2 \%)\end{array}$ & $\begin{array}{c}\text { Normal }(\geq 8 \mathrm{nmol} / \mathrm{L}) \\
(\mathrm{n}=223)(86.8 \%)\end{array}$ & Mean \pm SD & $\begin{array}{l}\text { Median } \\
\text { (Min-Max) }\end{array}$ \\
\hline Central & $2(9.09 \%)$ & $20(90.91 \%)$ & $14.05 \pm 5.76$ & $\begin{array}{c}13.35 \\
(4.7-30.30)\end{array}$ \\
\hline Eastern & $1(5.26 \%)$ & $18(94.74 \%)$ & $14.16 \pm 3.11$ & $\begin{array}{c}14.30 \\
(7.50-22.40)\end{array}$ \\
\hline Northern & $0(0 \%)$ & $15(100 \%)$ & $17.02 \pm 4.34$ & $\begin{array}{c}16.90 \\
(10.10-23.10)\end{array}$ \\
\hline Northeastern & $7(15.22 \%)$ & $39(84.78 \%)$ & $12.88 \pm 5.06$ & $\begin{array}{c}12.80 \\
(4.06-25.50)\end{array}$ \\
\hline Southern & $1(6.25 \%)$ & $15(93.75 \%)$ & $14.30 \pm 5.56$ & $\begin{array}{c}12.60 \\
(6.39-29.90)\end{array}$ \\
\hline$p$-value & & & 0.04 & \\
\hline
\end{tabular}

Testosterone classified by age groups $(<40,40-60$ and $>60$ years old $)$ was mainly divided into 2 types (low and normal levels). The prevalence of low testosterone level was $6.6 \%(n=9)$ among Thai orthopedic surgeans aged $<40$ years old $(n=136)$ and $20.7 \%(n=25)$ aged $>40$ years old $(n=121)$.

Table 5. PSA level classified by age and region of residence

\begin{tabular}{|c|c|c|c|c|}
\hline \multirow[t]{2}{*}{ Age group } & \multicolumn{4}{|c|}{ Testosterone level } \\
\hline & $\begin{array}{c}\text { High }(>4 \mathrm{ng} / \mathrm{ml}) \\
(\mathrm{n}=12)(4.7 \%)\end{array}$ & $\begin{array}{c}\text { Normal }(0-4 \mathrm{ng} / \mathrm{ml}) \\
(\mathrm{n}=245)(95.3 \%)\end{array}$ & Mean \pm SD & $\begin{array}{c}\text { Median } \\
\text { (Min-Max) }\end{array}$ \\
\hline$<40$ years & $1(0.45 \%)$ & $135(61.08 \%)$ & $0.83 \pm 0.83$ & $\begin{array}{c}0.66 \\
(0.17-8.31)\end{array}$ \\
\hline $40-60$ years & $4(1.81 \%)$ & $81(36.65 \%)$ & $1.41 \pm 3.34$ & $\begin{array}{c}0.80 \\
(0.20-30.00)\end{array}$ \\
\hline$>60$ years & $7(19.44 \%)$ & $29(80.60 \%)$ & $2.40 \pm 2.53$ & $\begin{array}{c}1.47 \\
(0.35-12.50)\end{array}$ \\
\hline$p$-value & & & $<0.001$ & \\
\hline Bangkok & $9(6.47 \%)$ & $130(93.53 \%)$ & $1.46 \pm 2.93$ & $\begin{array}{c}0.79 \\
(0.17-30.00)\end{array}$ \\
\hline Central & $0(0 \%)$ & $22(100 \%)$ & $0.87 \pm 0.60$ & $\begin{array}{c}0.69 \\
(0.19-2.59)\end{array}$ \\
\hline Eastern & $1(5.26 \%)$ & $18(94.74 \%)$ & $1.22 \pm 1.09$ & $\begin{array}{c}0.82 \\
(0.38-4.55)\end{array}$ \\
\hline Northern & $1(6.67 \%)$ & $14(93.33 \%)$ & $1.13 \pm 2.01$ & $\begin{array}{c}0.58 \\
(0.24-8.31)\end{array}$ \\
\hline Northeastern & $1(2.17 \%)$ & $45(97.83 \%)$ & $0.99 \pm 0.95$ & $\begin{array}{c}0.74 \\
(0.23-4.26)\end{array}$ \\
\hline Southern & $0(0 \%)$ & $16(100 \%)$ & $0.73 \pm 0.24$ & $\begin{array}{c}0.66 \\
(0.34-1.30)\end{array}$ \\
\hline$p$-value & & & 0.43 & \\
\hline
\end{tabular}

PSA level classified by age groups ( $<40,40-60$ and $>60$ years old) was divided into 2 types (high and normal levels). The prevalence of high PSA level among Thai orthopedic surgeans was $2.3 \%(n=5)$ aged $<60$ years old $(n=221)$ and $19.4 \%(n=7)$ aged $>60$ years old $(n=36)$. 
different age groups (One-way ANOVA, $p<0.001$ ). The prevalence of high PSA level was highest in the age group of $>60$ years old. However, no significant association was found between region of residence and total PSA.

\section{Discussion}

Several studies in Thailand demonstrated the prevalence of vitamin D deficiency. Soontrapa, et al. ${ }^{(5)}$ found that $66.3 \%$ of elderly Thai women residing in Khon Kaen Province had vitamin D deficiency [25(OH)D level $<35 \mathrm{ng} / \mathrm{mL}$ ] while the largest study of vitamin D status in a normal population $(\mathrm{N}=2641)$ identified overall $45.2 \%$ of vitamin D inadequacy. ${ }^{(6)}$ However, none of these studies focused on vitamin D inadequacy among Thai orthopedic surgeons. Most are indoor workers at high risk to develop vitamin D insufficiency because their lifestyles and regular work at the hospital and usually limited their exposure to sunlight. Additionally, some orthopedic surgeons are aging and could develop hypogonadism and prostatic hypertrophy.

The review of vitamin D status showed that $88.1 \%$ of subjects presented in populations worldwide had mean $25(\mathrm{OH}) \mathrm{D}$ values below $30 \mathrm{ng} / \mathrm{mL} .{ }^{(7)} \mathrm{In}$ addition. A systematic review in 2017 revealed that the prevalence of vitamin D inadequacy $(<30 \mathrm{ng} / \mathrm{mL})$ among physicians was as high as $95.7 \% .{ }^{(8)}$ One study about vitamin D status among Thai physicians revealed that none of the Thai dermatologists had serum $25(\mathrm{OH})$ D sufficiency, $38(38.78 \%)$ had vitamin D insufficiency $(20-30 \mathrm{ng} / \mathrm{mL})$ and $60(61.22 \%)$ had vitamin D deficiency $(<20 \mathrm{ng} / \mathrm{mL}) .{ }^{(9)}$ In this study, the prevalence of vitamin D inadequacy among Thai orthopedic surgeons (72.0\%) was significantly higher than that of normal Thai populations $(45.2 \%)^{(6)}$ and elderly Thai women $(66.3 \%) .{ }^{(5)}$ The differences in latitude (geographical location), weather, pollution, degree of expose to UVB, using sunscreen, skin color, cultural traditions (clothing), diets and sex could constitute the reasons. Age could be another factor because vitamin $\mathrm{D}$ production in the skin declines with increasing age. The results from this study demonstrated that vitamin D inadequacy was not only a major problem in Thai populations, but also common among Thai orthopedic surgeons. Vitamin D inadequacy among Thai orthopedists may represent the overall vitamin D inadequacy in Asian orthopedic surgeons. This data comprises important information to promote self-awareness because the orthopedic field always requires powerful muscle and bone strength. Moreover, further studies need to determine the correlation of any clinical risk factors and vitamin D levels among Thai orthopedic surgeons.

The differences of testosterone and PSA levels in different age group were significant as we expected; male testosterone normally tends to decline but PSA tends to become higher with increasing age. However, our results illustrated that mean testosterone level was not higher among those patients with age more than 60 years compared with those 40-60 years old (12.54 vs. 12.41 , respectively). A relatively small number of patients in each age group constituted one of limitations in this study. Moreover, information of underlying diseases, medications and other activities, were not recorded from enrolled participants.

Even though several studies have demonstrated low testosterone associated with metabolic syndrome and cardiovascular events among Japanese men ${ }^{(11,12)}$, we still lacked data identifying low testosterone level and any clinical diseases in Thai populations. Our study comprised a preliminary study among Thai orthopedic surgeons and the results may be helpful to further investigate the association of testosterone level and clinical diseases in Thai populations.

\section{Conclusion}

The prevalence of vitamin D inadequacy among Thai orthopedic surgeons was surprisingly high. Greater self-awareness to reduce possible consequences associated with vitamin D inadequacy is important. Vitamin D supplementation including prevention strategies need to be promoted among healthcare professionals.

\section{Declaration of competing interest}

The authors declare they have no competing interests. 


\section{References}

1. ACOG Committee on Obstetric Practice. ACOG Committee Opinion No. 495: Vitamin

D: Screening and supplementation during pregnancy. Obstet Gynecol 2011; 118: 197-8.

2. Sprague S, Petrisor B, Scott T, Devji T, Phillips $\mathrm{m}$, Spurr H, et al. What is the role of D supplementation in acute fracture patients? A systematic review and meta-analysis of the prevalence of hypovitaminosis $\mathrm{D}$ and supplementation efficacy. J OrthopTrauma 2015; 30: 53-63.

3. Holick MF, Binkley NC, Bischoff-Ferrari HA, Gordon CM, Hanley DA, Heaney RP, et al. Evaluation, treatment, and prevention of vitamin D deficiency: An Endocrine Society clinical practice guideline. J Clin Endocrinol Metab 2011; 96: 1911-30.

4. Soontrapa S, Soontrapa S, Chailurkit L. The prevalence and the calcidiol levels of vitamin D deficiency in the elderly Thai women in municipality of Khon Kaen province, Thailand. Srinagarind Med J 2002; 17: 231-8.
5. Chailurkit L, Aekplakorn W, Ongphiphadhanakul B. Regional variation and determinants of vitamin D status in sunshine-abundant Thailand. BMC Public Health 2011; 11: 853.

6. TutawornT,PhruetthiphatO, SongpatanasilpT. Prevalence and Clinical Correlation of Vitamin D Inadequacy in Traumatic Hip Fracture among Elderly Patients. J Ortho Bone Disord 2019, 3: 000191.

7. AkishitaM,FukaiS,HashimotoM,Kameyama Y, Nomura K, Nakamura T, et al. Association of low testosterone with metabolic syndrome and its components in middle-aged Japanese men. Hypertens Res 2010; 33: 587-91.

8. Akishita M, Hashimoto M, Ohike Y, Ogawa $\mathrm{S}$, Iijima $\mathrm{K}$, Eto $\mathrm{M}$, et al. Low testosterone level as a predictor of cardiovascular events in Japanese men with coronary risk factors. Atherosclerosis 2010; 210: 232-6. 